\title{
CONCEPT AND PRACTICE OF TEACHING TECHNICAL UNIVERSITY STUDENTS TO MODERN TECHNOLOGIES OF 3D DATA ACQUISITION AND PROCESSING: A CASE STUDY OF CLOSE-RANGE PHOTOGRAMMETRY AND TERRESTRIAL LASER SCANNING
}

\author{
Iulia Kravchenko a, Thomas Luhmann ${ }^{\text {b }}$, Roman Shults ${ }^{\text {a }}$ \\ ${ }^{a}$ Kyiv National University of Construction and Architecture, Faculty for Geoinformation Systems and Territory Management, \\ Povitroflotskyi Avenue, 31 Kyiv, 03038, Ukraine, Kravchenko_jv@ukr.net, r-schultz@mail.ru \\ b Jade University of Applied Sciences, Institute for Applied Photogrammetry and Geoinformatics, \\ Ofener Str. 16/19, 26121 Oldenburg, Germany, luhmann@jade-hs.de
}

Commission VI, WG VI/3

KEY WORDS: teaching concept, 3D data, terrestrial laserscanning, photogrammetry, international project

\begin{abstract}
:
For the preparation of modern specialists in the acquisition and processing of three-dimensional data, a broad and detailed study of related modern methods and technologies is necessary. One of the most progressive and effective methods of acquisition and analyzing spatial data is terrestrial laser scanning. The study of methods and technologies for terrestrial laser scanning is of great importance not only for GIS specialists, but also for surveying engineers who make decisions in traditional engineering tasks (monitoring, executive surveys, etc.). The understanding and formation of the right approach in preparing new professionals need to develop a modern and variable educational program. This educational program must provide effective practical and laboratory work and the student's coursework. The resulting knowledge of the study should form the basis for practical or research of young engineers. In 2014, the Institute of Applied Sciences (Jade University Oldenburg, Germany) and Kyiv National University of Construction and Architecture (Kiev, Ukraine) had launched a joint educational project for the introduction of terrestrial laser scanning technology for collection and processing of spatial data. As a result of this project practical recommendations have been developed for the organization of educational processes in the use of terrestrial laser scanning. An advanced project-oriented educational program was developed which is presented in this paper. In order to demonstrate the effectiveness of the program a 3D model of the big and complex main campus of Kyiv National University of Construction and Architecture has been generated.
\end{abstract}

\section{INTRODUCTION}

The modern world creates its own demands. In the context of the incredible mobility of people on the planet and the absolute availability of communications in all parts of the globe, the educational process cannot be kept away from these global processes. Today students have a wide range of possibilities to get an education in most universities in the world. The only restrictions might be financial conditions and varieties of cultural and religious principles of society. The necessary conditions for education in other countries are knowledge of modern computer and communication technologies and a high level of foreign language skills (mostly English). With the required level of training in communication, language and cultural environment and financial support through grants, government programs and sponsorship student can establish wider educational projects and achieve desired goals in education.

However, students alone cannot manage these objectives. The student can realize his opportunities for mobility only if the training programs and qualifications for the specialist are the same in all countries. Formation of skill requirements and the creation of unified integrated programs are the most important tasks of today's higher level education (Veenendaal, 2014). This problem can be solved only by the cooperative efforts of teachers and scientists from different organizations and countries (Jordan et al., 2012). Within this context we present the results of cooperation between the University of Applied
Sciences Oldenburg (Germany) and Kyiv National University of Construction and Architecture (Ukraine) in the field of photogrammetry, geoinformatics and geodesy. The presented results relate to the issues of training to modern technology of spatial data collection through the example of "Close-range photogrammetry and laser scanning". This course is new for the students and staff of Kyiv National University of Construction and Architecture. The development of modern educational program was possible thanks to the cooperation with the Jade University of Applied Sciences of Oldenburg.

\section{EDUCATION IN UKRAINE}

First of all we would like to say a few words about the basic principles of education in Ukraine. Ukraine has a five-level educational system: Junior Bachelor (2 years), Bachelor (2 years), Master (1.5-2 years), PhD (3 years) and Doctor of Science (2 years). At the level of Junior Bachelor and Bachelor training is done in "Geodesy and Land Management" specialty which refers to the two branches of knowledge "Building and Architecture" and "Earth Science". At the master's level different specializations are released, for instance "Surveying", "Applied geodesy", "Space geodesy" "Space monitoring of the Earth", "GIS technologies", "Photogrammetry and remote sensing", "Cartography", "Land management and cadastre" and so forth. At the PhD level and Doctor of Science there are two isolated specialties: "Geodesy, photogrammetry and cartography" and "Cadastre and monitoring of land". Such educational structure in general corresponds to the structure of 
European education (Law of Ukraine, 2014). However, such compliance exists only in theory, the content of educational programs in Ukraine differs greatly from the European system. For the purpose of greater integration of educational programs in Kyiv National University of Construction and Architecture (KNUCA) it was made a decision to introduce new directions that would be consistent with existing structures in the world. One of such directions is terrestrial laser scanning. Until recently, the structure of the curriculum didn't have any special course on the use and implementation of terrestrial laser scanning technology. At the same time, all developed universities in the world have such a course.

For many years, students of KNUCA, specialty "Geodesy" and "GIS technology", are taught in "Engineering Photogrammetry". The structure of this course does not include a supplement large section devoted to the use of scanning technologies. Therefore, it was decided to introduce a new course in "terrestrial laser scanning." Due to the lack of experience in organizing such courses the experience of the Jade University was used, as one of the best known in this area of education.

\section{INTERNATIONAL COOPERATION}

For maximum effect an agreement on cooperation in education between the KNUCA Department of Photogrammetry and Geoinformatics and the Institute of Applied Photogrammetry and Geoinformatics of Oldenburg (IAPG) was signed in 2013. Training programs and joint conferences, presentations, seminars, training and professional development of the teaching staff of universities, as well as projects on student exchange were provided as a part of this agreement.

At the first stage of our program teachers of KNUCA, Ph.D. Kravchenko J. and assistant Kvartych T., had an educational visit to the Oldenburg institute in summer 2013 (Fig. 1). From the educational point of view, the main idea was to train KNUCA teachers gradually by modern technology of 3D data acquisition and to initiate the learning process of KNUCA teachers.

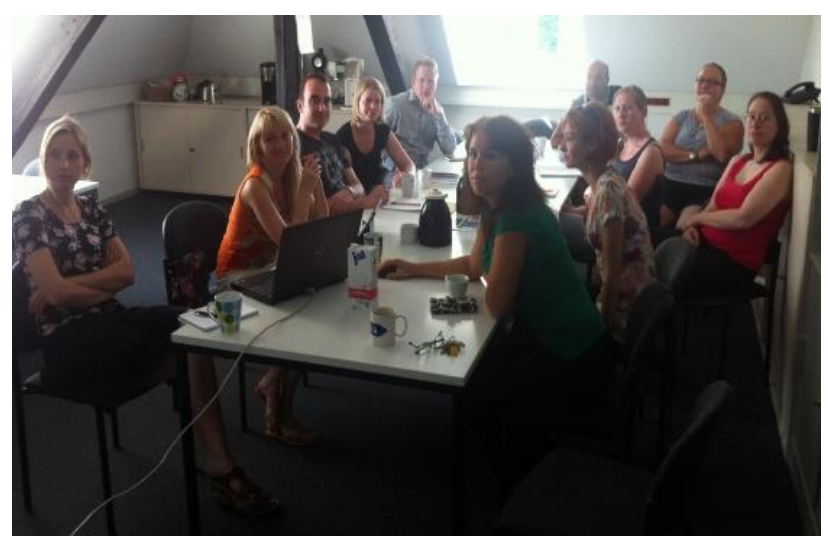

Fig. 1. Presentation of KNUCA at IAPG

The main educational activities included:

- training of modern measurement equipment that included practice of camera calibration and work with laser scanners,

- visit to "AXIOS 3D Services",

- visit to Hafen City University, Hamburg,

- research of image analyst in software ArcGIS and ERDAS.

As a result of this visit, an agreement on cooperation between IAPG and KNUCA was signed.
The members of the Department of Geoinformatics and Photogrammetry were invited to scientific-oriented visit to the IAPG in Oldenburg for the period of July 1 to August 9, 2014. The main activities were including:

- preparing a teaching workshop in KNUCA for November 2014 ,

- preparing a joint Tempus project,

- discussing the exchange of students between KNUCA and Jade University in 2015,

- training in PhoX software,

- lectures about Remote Sensing at Department of GIS and photogrammetry,

- training in iWitness software,

- training in laser scanning,

- training in AICON 3D Studio software,

- training in laser scanning including software for data processing.

Especially for KNUCA students a course on technology of terrestrial laser scanning and terrestrial photogrammetry was offered. Further to cooperation on November 3-7, 2014 Prof. Thomas Luhmann gave lectures for students of 3th semester of specialty "Geographic Information Systems and Technologies", "Geodesy", "Land management and cadastre". A series of lectures was consolidated under the common name "Closerange photogrammetry and laser scanning", assisted by D. Gorkovchuk (KNUCA). The lectures addressed the following issues: Basics (working with laserscanners, method of distance measurements); Measurement uncertainty of terrestrial laserscanners; Registration/transformation of point clouds; Special interests; Impressions (applications). An additional series of lectures was read to the students of specialty "Geographic Information Systems and Technologies" by Thomas Willemsen, who is university lecturer of the Hafen City University (HCU) Hamburg, Germany, in the Department of Built Environment And Metropolitan Development. Along with lectures practical exercise in laser scanning were conducted. During the workshops students learn about the latest advances in the field of close-range photogrammetry and laser scanning, acquired practical skills of data collection using modern equipment: photogrammetric camera and laser scanner FARO Focus 3D 120 that were provided by the Jade University (Fig. 2). As the object for terrestrial laser scanning the sports complex of KNUCA and a church in the park to n.a. N.Ostrovsky in Kiev were selected (Fig. 3).

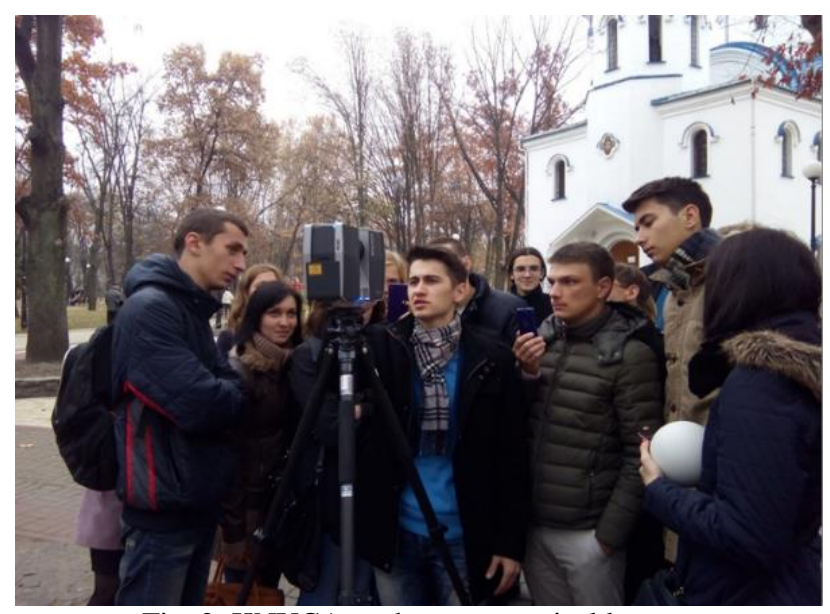

Fig. 2. KNUCA students at practical lessons 


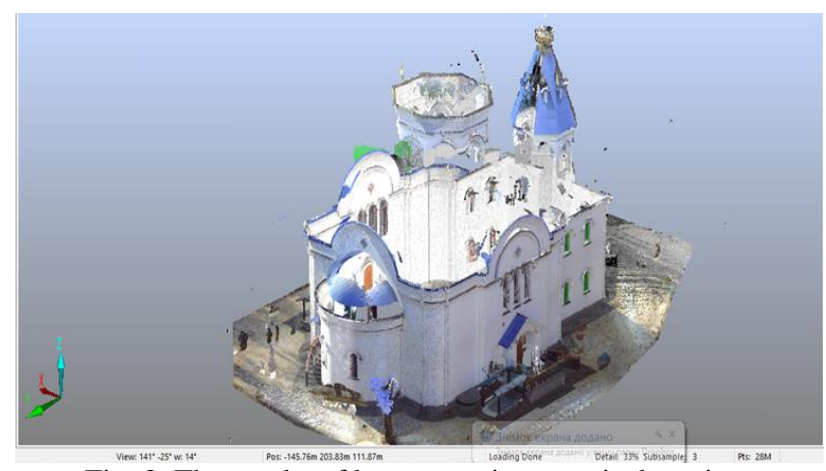

Fig. 3. The results of laser scanning practical seminar

In order to determine the effectiveness of the workshop a course of lectures evaluation was performed among the students of specialty "Geographic information systems and technologies." We have proposed to use the method of questioning. The questionnaire contained four sets of issues: Lectures, Exercises, Course literature and Overall Evaluation of the course. The average value serves as an indicator of the quality of the responses for each cluster (see Fig. 4). The questionnaire listed the following issues:

\section{General questions}

1. Is the learning outcome well-defined for the course?

2. How is your background knowledge related to this course?

Lectures

3. What do you think of the content of the lectures?

4. What do you think of the lecturers' subject competence?

5. Did the lecturers succeed in transferring new knowledge to the students?

6. Did the lectures increase your interests in the subjects?

Exercises/lab work

7. How is the content of the exercises?

8. Are exercise tasks too difficult? ( $1=$ very easy; $5=$ very difficult)

9. Is the lab facility satisfactory for performing the exercises?

\section{Course literature}

10. Is the course literature/material sufficient?

11. Is the course literature/material easy to understand?

12. How are the written instructions for exercise tasks/lab work?

\section{Overall evaluation of this course}

13. Does the course meet your expectations?

14. Has the course achieved the stated outcomes?

15 . What is your overall grade for the course as a whole?

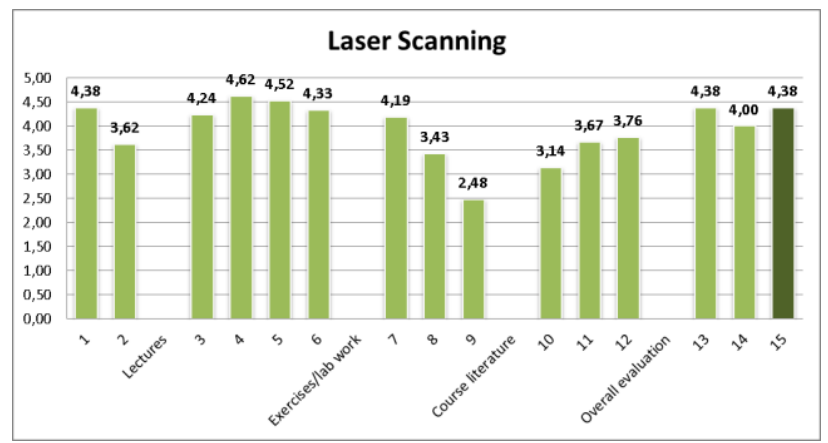

Fig. 4. The results of questionnaire

The analysis of the distribution of average total marks indicates a low level of logistical and methodological support. We should note highly qualified and professional level of teachers that confirm high marks on the block of question about Lectures. The evaluation of quality of the workshop through an anonymous questionnaire of students makes it possible to detect weaknesses and areas of development that are relevant for further improvement of the courses at KNUCA. With respect to low marks in the evaluation question numbers $10,11,12$, active work staff of the department should be directed to the development of new teaching materials, textbooks, tutorials etc.

\section{JOINT STUDENT PROJECT}

To improve students' practical training and intercultural competences an exchange of students between KNUCA and Jade University was organized from 3 to 24 of May 2015. The selection of students was carried out according to the following criteria: academic performance, English language skills, communication skills, knowledge of modern information technology. The project was conducted in two stages:

1) Field work: held from May 3 to 10 at KNUCA university.

2) Data processing: conducted at computer laboratory of the Jade University in Oldenburg from May 17 to 24.

At the work organization, we had used the principles that are presented in (Ronnholm et al., 2007; Boehler \& Marbs, 2004).

Field work included:

- - project planning

- - creating of geodetic network,

- - photogrammetry,

- - laser scanning.

We formed two groups of students. One from Ukrainian students and one from German students. During the works at Kiev, a group of German students lived in the student campus of the Faculty of GIS and territory management. The work was organized so that the students all the time had to discuss to the correct execution of the task. For example, one group performed field geodetic work for the second group that used the survey data as a reference for laser scanning and close-range photogrammetry. The students communicated with each other in English without any problems. The major part of work was carried out by students themselves. KNUCA teacher only played an advisory role.

Geodetic network was created as a traverse around the main and laboratory buildings of the university. The work was performed with a Leica TS06 total station. In parallel, control points of buildings were measured. Geodetic measurements were processed in Leica GeoOffice software immediately after the field work for rapid error detection and correction. Finally the network with 11 stations and more than 100 control points was built. The mean square error of a network was $8 \mathrm{~mm}$.

Photogrammetry works were performed with cameras Nikon D300, Nikon D3200 and Sony Alpha A57 taking pictures of main building, laboratory and architectural departments, sport complex, monument near the main building and church. About 7000 photos were taken.

Laser scanning was performed with Faro Focus3D and Leica Scanstation C10 scanners. The left side of the front façade of the main building was scanned with the Faro scanner. 17 scans with 280 million points were collected. The rest of the building was scanned with the Leica scanner. 26 scans with 340 million points were received.

Every day after work, the German students had an interesting social program. Especially popular were evening walks in the 
historical part of Kiev. At this time, they had the opportunity to have an informal talk with their Ukrainian contemporaries and to intensify their cultural skills.

In a subsequent week the same groups of students has continued with post-processing of the data at Jade University. Data processing included:

- photogrammetric processing

- laser scanning processing

- 3D modelling.

Photogrammetry work was performed in iWitness software (Photometrix). 3D models of the monument, the sport complex and the parking entrance were created. Main building photo processing was very complicated due to extremely large number of pictures. Creating the model of the church using photos was significantly complicated due to completely white walls, where identification of corresponding points is very difficult.

Laser scanning data processing was performed in Faro Scene and Leica Cyclone software for Faro Focus3D and Leica Scanstation C10 scanners, respectively. Registration of Faro data was conducted during post processing in Faro Scene software. Spherical and black-and-white targets identification was used for registration. The registration accuracy was reported to $4 \mathrm{~mm}$. Registration of Leica data was performed directly in the field during measurement with scanner software. Only clouds optimization was performed in Cyclone. The registration error was $8 \mathrm{~mm}$.

CloudCompare software was used for merging data from different scanners. Cloud-to-cloud registration method was used. The global registration error was $4 \mathrm{~cm}$. Such gross error is explained by the lack of common targets for Faro and Leica scans and "open" scanning network for both scanners. Point cloud processing was performed in various software packages:

1) PointTools - 3D point cloud visualization, "fly-through" video

2) GeoMagic - point cloud meshing

3) AutoCAD - solid model creation

The results of the students' works are presented below.

On Fig. 5 and 6 the results of terrestrial laser scanning are presented.

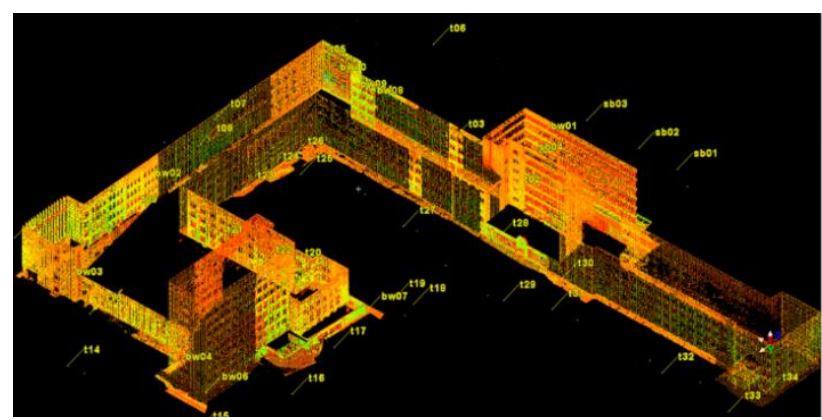

Fig. 5 Point cloud model of KNUCA main building

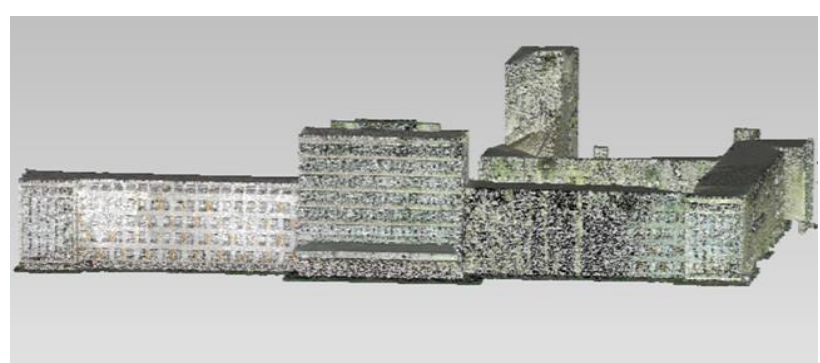

Fig. 6. Mesh created from point cloud

Next, the students were obtained 3D model by close-range photogrammetry, which is represented on Fig. 7.

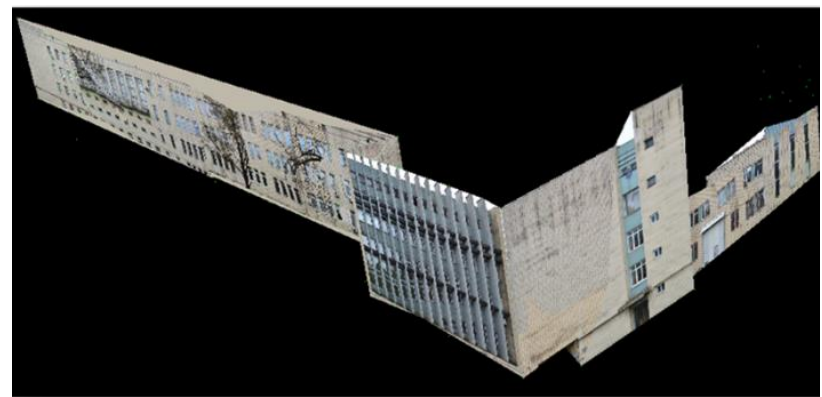

Fig.7. Polygonal model of a laboratory department, created from photos

As a result of the combined data of terrestrial laser scanning and close-range photogrammetry the 3D model of KNUCA main building was obtained (Fig. 8).

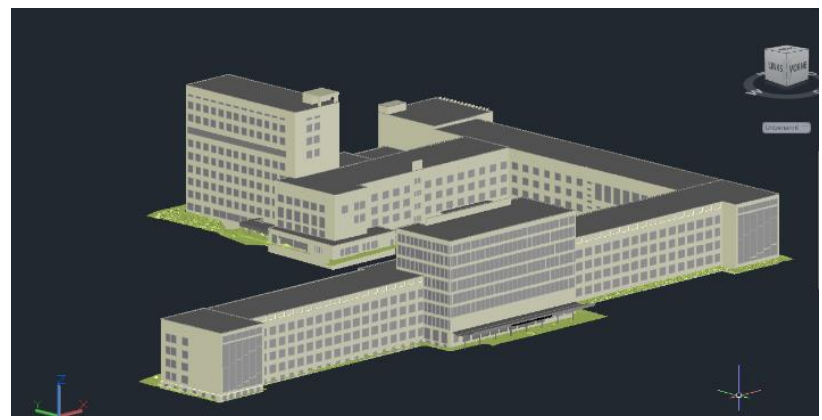

Fig.8. Final 3D model of main building

To analyze the effectiveness of student exchange practice the members of the Department of Geoinformatic and photogrammetry were invited to scientific-oriented visit to Institute of Applied Photogrammetry and Geoinformatics in Oldenburg for the period of July 4 to August 1, 2015. The main activities were including:

- preparing workshop in KNUCA at September 2015,

- discussing exchange of students between KNUCA and Jade University in 2016: analyse results and conclusion

- training in Lidar data processing with PostGIS

- training in using spatial web-services for publication of spatial data

- training in comparison of effectiveness of DTM creation methods in instrumental GIS and spatial DBMS

- training in advanced querying in Postgres

- participation on GIN-Forum about Mobile systems: Apps, GPS and geo data

In October 2015 Prof. Thomas Luhmann again gave the similar course for the students of 6th semester of specialty "Geographic 
Information Systems and Technologies", "Geodesy", "Land management and cadastre".

The result of this scientific and educational work was the new course "terrestrial laser scanning," which in 2016 included in the curriculum of specialty "Geographic Information Systems and Technologies", "Geodesy", "Land management and cadaster» for the $9^{\text {th }}$ semester. A methodical complex has been developed which includes curriculum guidelines and a tutorial for the course of terrestrial laser scanning. The structure of the curriculum of the course meets all modern requirements. The course structure "terrestrial laser scanning" consists of the following sections:

Lecture 1. The history of the technology of terrestrial laser scanning.

Lecture 2. Classification of tasks to be solved by terrestrial laser scanning and analysis of the current state of the use of terrestrial laser scanning in solving practical engineering problems.

Lecture 3. The structure and operation of ground-based laser scanners. Pulse, phase and laser triangulation scanners.

Lecture 4. Modern software for execution, processing and modelling of terrestrial laser scanning data.

Lecture 5. Accuracy and error propagation of terrestrial laser scanning.

Lecture 6. Design work on the implementation of terrestrial laser scanning. The sequence of actions during field work.

Lecture 7. Methods and models of pre-processing of terrestrial laser scanning. Overview of the functions of different software.

Lecture 8. Methods and models linking individual laser scans to create a 3D model. Orientation pattern in the global coordinate system. Overview of the functions of different software.

Lecture 9. The principles and approaches of three-dimensional modelling of objects from laser scanning data.

Lecture 10. Methods of calibration of terrestrial laser scanners in the field and laboratory conditions.

Lecture 11. Technology integrated use of terrestrial laser scanning and digital photogrammetry.

Lecture 12. Creation of 3D models with high texture.

Lecture 13. Technology perform field and office work in solving problems of design, survey and monitoring data on terrestrial laser scanning.

Lecture 14. Special application of terrestrial laser scanning archaeological survey, reverse engineering, engineering and geodetic survey.

This course structure displays all the modern approaches in teaching of terrestrial laser scanning in the best universities of the world. Practical work includes work with the terrestrial laser scanner in the field and further office processing of scan data. The program also provides for implementation of the course of works on the calculation of the estimated parameters of scanning and preliminary calculation of the accuracy of the scan.

\section{CONCLUSIONS}

First of all, we want to note that the results have exceeded our expectations. By working together, we have raised the professional level of teachers' KNUCA. The quality of students training was increased. At last, work have contributed to the beginning of the scientific cooperation between our universities.
- Improve the existing curriculum of discipline "Terrestrial Photogrammetry";

- Extension of the practice of student exchange between the universities based on integrated training curriculum;

- To simplify the exchange of students organization of English language courses;

- Joint research in the sector of geoinformatics and photogrammetry with further presentation of these studies in the international scientific and educational congresses and conferences.

After the implementation of the educational project, we plan to organize a joint annual international conference in the format of Oldenburg - Kiev. The conference materials are planned to use for creation of international scientific publication on GIS, geodesy and photogrammetry.

We hope that the experience presented here will be useful to students and teachers of other universities in the organization of new courses and the upgrading of existing courses on the modern technology of collecting spatial data.

\section{ACKNOWLEDGEMENTS}

We gratefully acknowledge the financial support of the Funds for Internationalization of Jade University of Applied Sciences in Germany and the Ministry for Sciences and Culture of Lower Saxony.

We like to thank the teachers and all active participants from both Universities who contributed to the success of cooperation.

We also like to thank our student Nina Grondstein for the completion of the 3D model of KNUCA main building.

\section{REFERENCES}

Boehler, W., Marbs, A., 2004. 3D Scanning and Photogrammetry for Heritage Recording: a Comparison. Proceeding $12^{\text {th }}$ International Conference on Geoinformatics, University of Gavle, Sweden.

Jordan, T.R., Madden, M., Sharma, J.B., Panda, S.S., 2012. Applied Geospatial Education: Acquisition and Processing of High Resolution Airborne Lidar and Orthoimages for The Great Smoky Mountains National Park, Southeastern United States. XXII ISPRS Congress, Technical Commission VI, Melbourne, Australia, Vol. XXXIX-B6, pp. 53-57.

Law of Ukraine "About Higher Education", 2014. Verkhovna Rada of Ukraine; Law of 01.07.2014 № 1556-VII.

Ronnholm, P., Honkavaara, E., Litkey P., Hyyppa H., Hyyppa J., 2007. Integration of Laser Scanning and Photogrammetry. Proceedings of the ISPRS Workshop 'Laser Scanning 2007 and SilviLaser 2007', Espoo, Finland, Vol. XXXVI, Part 3, pp. 355362.

Veenendaal, B., 2014. Addressing the Challenges of a Quarter Century of Giscience Education: A Flexible Higher Education Curriculum Framework. ISPRS Technical Commission VI Symposium, Wuhan, China Vol. XL-6, pp. 107-112.

Our further plan includes the modernization of course about the application of terrestrial photogrammetry. Implementation of this plan will include the following elements: 